\title{
Article
}

\section{The Relationship between Birth Weight Discordance and Adverse Infant Mortality among Monozygotic and Dizygotic Twins in Japan, 1995-2008}

\author{
Yoko Imaizumi \\ The Center for Twin Research, Graduate School of Medicine, Osaka University, Suita City, Osaka, Japan
}

\begin{abstract}
Using vital statistics in Japan (1995-2008), 154,578 live-born twin pairs (128,236 monozygotic [MZ] and 180,920 dizygotic [DZ]) were identified. The proportion of severe discordance among live-born twin births was twice as high in Japanese than Caucasian infants. There were $1858 \mathrm{MZ}$ and $1620 \mathrm{DZ}$ infant deaths. Computation of the relationship between infant mortality rate and birth weight discordance among the twins was performed. Discordance levels were classified into seven groups: $<5 \%$, five groups from $5-9 \%$ to $25-29 \%$, and $\geq 30 \%$. The mortality rate was significantly higher in MZ than DZ twins for discordances except at 5-9\% and 10-14\%. The lowest rate for MZ twins was at 5-9\% (7.5 per 1000 live twins) and significantly increased from $10-14 \%(9.4)$ to $\geq 30 \%$ (83.4), while the lowest rate for DZ twins was at $<5 \%(6.7)$, which significantly increased at $10-14 \%$ (8.0) and from $25-29 \%$ (12.1) to $\geq 30 \%$ (35.5). The relationship was also computed in two gestational age groups ( $<28$ and $\geq 28$ weeks). For births at $<28$ weeks, three discordances (after 20-24\%) in MZ twins were associated with adverse mortality rate. For births at $\geq 28$ weeks, the same relationship was obtained after 10-14\% in MZ and after 20-24\% in DZ twins. The relationship from 2002 to 2008 showed that the mortality rates significantly increased after 10$14 \%$ for both types of twins. In conclusion, five discordance levels in $\mathrm{MZ}$ and three levels in $\mathrm{DZ}$ twins were associated with adverse mortality rates.
\end{abstract}

Keywords: Infant mortality; twins; birth weight discordance; gestational age

(Received 21 October 2019; accepted 25 November 2019; First Published online 6 April 2020)

According to Imaizumi (2015), the infant mortality rates (IMRs) for monozygotic (MZ) and dizygotic (DZ) twins decreased by one-half from 1995 to 2007 in Japan, where the rate was two times higher in $\mathrm{MZ}$ than in DZ twins. As for maternal ages, IMRs for both $\mathrm{MZ}$ and $\mathrm{DZ}$ twins were significantly higher at maternal ages of $<20$ years than in other maternal age groups. Similarly, the IMRs in MZ twins significantly decreased from 696 (per 1000 live MZ twin births) at gestational age (GA) $<24$ weeks to 3 at 37 weeks, except at 36 weeks. Corresponding IMRs in DZ twins significantly decreased from 589 at GA $<24$ weeks to 1.9 at 39 weeks (except at $36-38$ weeks) and significantly increased to 4.8 at $\geq 40$ weeks.

According to Blickstein and Kalish (2003), approximately 75\% of live intrapair twins showed $<15 \%$ birth weight discordance (BWD). Between co-twins (concordant), 20\% were $15-24 \%$ (mildly) discordant, and approximately $5 \%$ were $\geq 25 \%$ (severely) discordant. Tobe et al (2010) also reported these proportions using a nationwide obstetric database of Japanese twins from 2001 to 2005. In the Japanese population, severe discordance was $10 \%$, a value that was two times higher than in the Caucasian population.

BWD is a risk factor for perinatal mortality in the USA (Branum \& Schoendorf, 2003; Kim et al., 2019), Japan (Kato \& Matsuda, 2006) and Canada (Jahanfar et al., 2017). It is also a risk

Author for correspondence: Yoko Imaizumi, Email: yoko3.imaizumi@gmail.com

Cite this article: Imaizumi Y. (2020) The Relationship between Birth Weight Discordance and Adverse Infant Mortality among Monozygotic and Dizygotic Twins in Japan, 1995-2008. Twin Research and Human Genetics 23: 55-60, https://doi.org/ 10.1017/thg. 2020.8 factor for neonatal mortality (Branum \& Schoendorf, 2003; Demissie et al., 2002; Kim et al., 2019; Mazhar \& Kanwal, 2010; Tobe et al., 2010).

The present study examines the relationship between IMRs and BWD levels among MZ and DZ twins. It also examines the effects of GA groups ( $<28$ weeks and $\geq 28$ weeks) and between two periods (1995-2001 and 2002-2008) on the relationship between IMRs and BWD levels.

\section{Materials and Methods}

\section{Data Sources}

Data on live births and infant deaths between 1995 and 2008 were obtained using Japanese vital statistics records. The Statistics and Information Department, Ministry of Health, Labour and Welfare (Tokyo, Japan) maintains records covering the entire Japanese population. Records in the form of live birth certificates include details about the nationality, sex, birth date, address, GA, birth weight (BW), parental birth dates and ages, single or twin births and birth order of twins. Death certificates contain the same information as live birth certificates (excluding paternal age) as well as the date of infant death.

\section{Data Analysis}

In the present study, 154,578 live-born twin pairs $(309,156$ liveborn twins) were estimated using the Weinberg (1901) method 
as $128,236 \mathrm{MZ}$ and $180,920 \mathrm{DZ}$ twins. These data were used as denominators to compute the IMRs according to BWD levels. Intrapair BWD was computed as follows: higher BW minus lower BW divided by higher BW and multiplied by 100 . This formula is also used to compute infant deaths. Number of infant deaths consists of two categories: live intrapair twins with both infant deaths (2Ds) and a surviving twin with an infant death (D). The former infant deaths were 553 twin pairs (1106 infant deaths) and the latter were 2372 infant deaths. Using the Weinberg method, these numbers of infant deaths (3478) were estimated as 1858 in MZ and 1620 in DZ twins. BWD levels were classified into the following seven groups: $<5 \%$, five groups from $5-9 \%$ to $25-29 \%$, and $\geq 30 \%$. The relationship between IMRs and BWD levels was computed for both types of twins. The relationship was also computed among two GA groups ( $<28$ and 28 weeks $\geq$ ) and for two periods (1995-2001 and 2002-2008).

\section{Results}

\section{Frequencies of BWD among Live-Born Twin Pairs}

Table 1 shows the distribution of BWD among live twin births during the period 1995-2008. The frequencies of BWD at $<5 \%$ were $32 \%$ in $\mathrm{MZ}$ and $26 \%$ in DZ twins. The corresponding proportions were at $5-9 \%$ for $25 \%$ and $24 \%$, at $10-14 \%$ for $17 \%$ and $19 \%$, at $15-19 \%$ for $10 \%$ and $13 \%$, at $20-24 \%$ for $6 \%$ and $8 \%$, at $25-29 \%$ for both $4 \%$, and at $\geq 30 \%$ for both $5 \%$, respectively. These proportions decreased with BWD levels, except at $\geq 30 \%$ for both MZ and DZ twins.

The total number of live-born twins was divided into two GA groups. For births that took place at $<28$ weeks, the proportions at $<5 \%$ and at $30 \% \geq$ in MZ twins were $24 \%$. In contrast, the corresponding values in $\mathrm{DZ}$ twins were $27 \%$ and $7 \%$, respectively. The value for $\mathrm{MZ}$ twins at $\geq 30 \%$ was 3.7 times higher than that for $\mathrm{DZ}$ twins. For births at $\geq 28$ weeks, the value at $\geq 30 \%$ was $5 \%$ for both $\mathrm{MZ}$ and DZ twins.

The total number of live twin births was divided into two periods: 1995-2001 (old) and 2002-2008 (recent). For the old versus the recent periods, concordant BWD levels at $<15 \%$ were $73 \%$ and $75 \%$ in $\mathrm{MZ}$ twins. The corresponding values in $\mathrm{DZ}$ twins were $70 \%$ for both periods. In contrast, severely discordant BWD levels at $\geq 25 \%$ were $10 \%$ versus $9 \%$ in $\mathrm{MZ}$ twins. The corresponding values were $9 \%$ for both periods in DZ twins.

\section{Relationship between IMRs and BWD in Twins}

Table 2 shows the relationship between IMRs and BWD levels for both $\mathrm{MZ}$ and DZ twins according to the survival states of twin pairs: 2Ds, D and total (2Ds plus D). For the 2Ds category, the lowest IMR was at $5-9 \%$ in MZ (2.4 per 1000 live twins) and in DZ (1.8) twins. The IMRs were significantly higher in MZ than in DZ twins except at two BWD levels (5-9\% and 15-19\%). The lowest IMR in MZ twins significantly increased with BWD except at $15-19 \%$ (2.8). Conversely, the lowest IMR in DZ twins only significantly increased at $10-14 \%$ (2.7). Specifically, the IMRs in $\mathrm{DZ}$ twins were similar for each BWD level except at $<5 \%$ and $10-14 \%$.

For the D category, the lowest IMR was at $<5 \%$ in MZ (4.8) and in DZ (4.1) twins. IMRs were significantly higher in MZ than in DZ twins from $15-19 \%$ ( 9.2 vs. 5.4 ) to $\geq 30 \%$ ( 50.7 vs. 32.8 ). Among $\mathrm{MZ}$ twins, the lowest IMR significantly increased with BWD from $15-19 \%$ to $\geq 30 \%$. In contrast, the lowest IMR in DZ twins significantly increased with BWD from $5-9 \%$ to $\geq 30 \%$.

For total number of infant deaths (2Ds plus D), the lowest IMRs were at $5-9 \%(7.5)$ in $\mathrm{MZ}$ twins and at $<5 \%$ (6.7) in DZ twins. IMRs were significantly higher in $\mathrm{MZ}$ than in DZ twins except at $5-9 \%$ and $10-14 \%$. For MZ twins, the lowest IMR significantly increased with BWD level from $10-14 \%$ (9.4) to $\geq 30 \%$ (83.4). For DZ twins, the lowest IMR significantly increased at $10-14 \%(8.0)$ and from $25-29 \%$ (12.1) to $\geq 30 \%$ (35.5).

\section{Relationship between IMRs and BWD Levels in Two GA Groups}

Table 3 shows the relationship between IMRs and BWD levels for both types of twins according to the two GA groups. Table 2 shows the proportions of $2 \mathrm{Ds}$ and $\mathrm{D}$ among the total infant deaths were $36.7 \%(682 / 1858)$ and $63.3 \%(1176 / 1858)$ in $\mathrm{MZ}$ twins. The corresponding values were $26.2 \%(424 / 1620)$ and $73.8 \%(1196 / 1620)$ in DZ twins.

For the group with GA $<28$ weeks, the IMRs among the $2 \mathrm{Ds}$ category were the lowest at $15-19 \%$ (66.1) in $\mathrm{MZ}$ and at $\geq 30 \%$ (91.7) in DZ twins. IMRs were significantly higher in MZ than in DZ twins for BWD levels at 10-14\% (184.6 in MZ and 107.1 in DZ twins) and at $\geq 30 \%$ (212.2 in $\mathrm{MZ}$ and 91.7 in DZ twins). In contrast, IMRs were significantly lower in $\mathrm{MZ}$ than in $\mathrm{DZ}$ twins at $15-19 \%$ (66.1 vs. 151.2 ) and $20-24 \%$ (91.6 vs. 159.1). The lowest IMR in MZ twins was significantly lower than the other values for BWD levels except at 20-24\%. Among DZ twins, the lowest IMR was obtained at $\geq 30 \%$. Therefore, BWD among the $2 \mathrm{Ds}$ category was not the risk factor for IMR for both MZ and DZ twins.

For the D category, the IMRs were the lowest at 15-19\% (107.4) in $\mathrm{MZ}$ and at $<5 \%$ (93.1) in DZ twins and were similar between twins in each BWD level. Although IMRs in MZ twins were similar in all BWD levels except at $\geq 30 \%$ (164.1), they increased in DZ twins with BWD levels at $10-14 \%(128.0), 15-19 \%$ (139.5) and $\geq 30 \%$ (183.4).

For overall infant deaths (2Ds plus D), the IMRs were the lowest at $15-19 \%$ (173.6) in MZ and at 5-9\% (207.2) in DZ twins and were significantly higher in MZ than in DZ twins at $10-14 \%$ and $\geq 30 \%$. Conversely, IMRs were significantly lower in MZ than in DZ twins at $15-19 \%$. The lowest IMR in MZ twins was significantly increased at $20-24 \%$ and thereafter. In contrast, the lowest IMR in DZ twins was only significantly increased for two BWD levels at $15-19 \%$ (290.7) and $\geq 30 \%$ (275.2).

For the group with $\mathrm{GA} \geq 28$ weeks, IMRs among category 2Ds were the lowest at $5-9 \%$ in $\mathrm{MZ}(0.6)$ and in DZ (0.3) twins. IMRs were significantly higher in $\mathrm{MZ}$ than in $\mathrm{DZ}$ twins in each BWD level. The lowest IMR in MZ twins was significantly increased with BWD after 10-14\% (1.5), while the lowest IMR in DZ twins was significantly increased at $10-14 \%(0.6)$. This suggests that BWD is not a risk factor for IMR among category $2 \mathrm{Ds}$ in DZ twins.

For category D, IMRs were the lowest at $<5 \%$ in MZ (2.9) and DZ (2.6) twins and were significantly higher in MZ than in DZ twins at $15-19 \%$ and thereafter. IMRs were significantly increased with BWD level at $10-14 \%$ and thereafter in $\mathrm{MZ}$ twins and at $5-9 \%$ and thereafter, except at $10-14 \%$ in DZ twins.

For the overall infant deaths, the IMRs were the lowest at $5-9 \%$ (3.9) in $\mathrm{MZ}$ and at $<5 \%$ (3.2) in DZ twins and were significantly higher in $\mathrm{MZ}$ than in DZ twins except at 5-9\%. As for MZ twins, the lowest IMR significantly increased with 


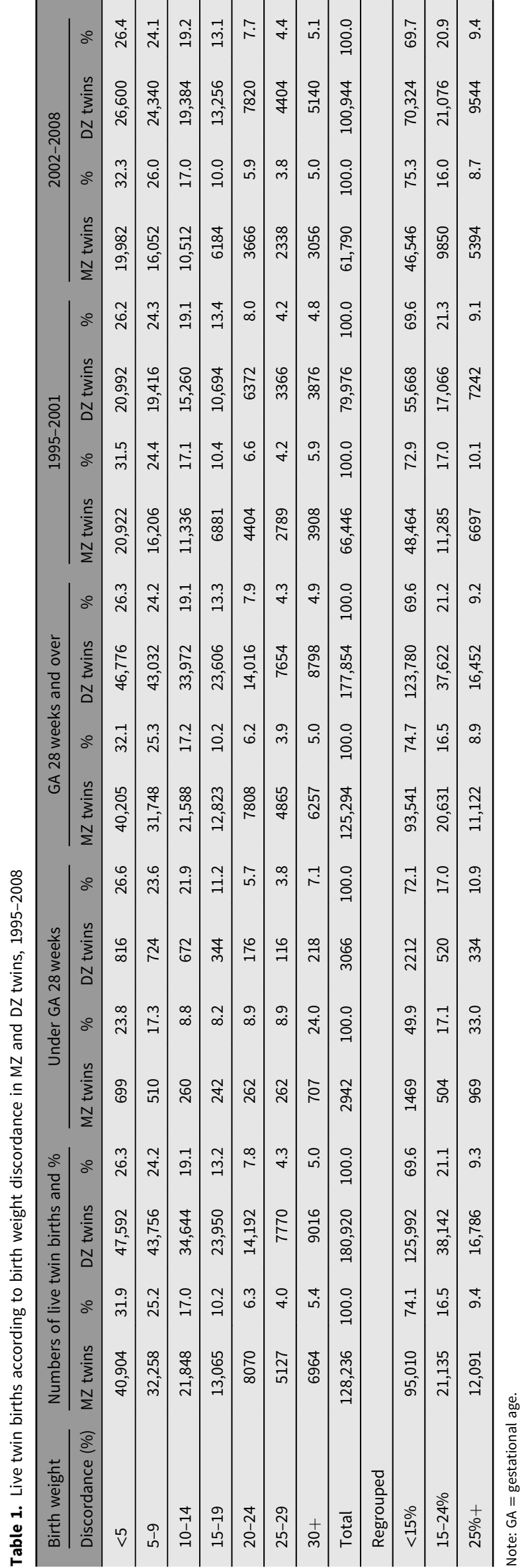

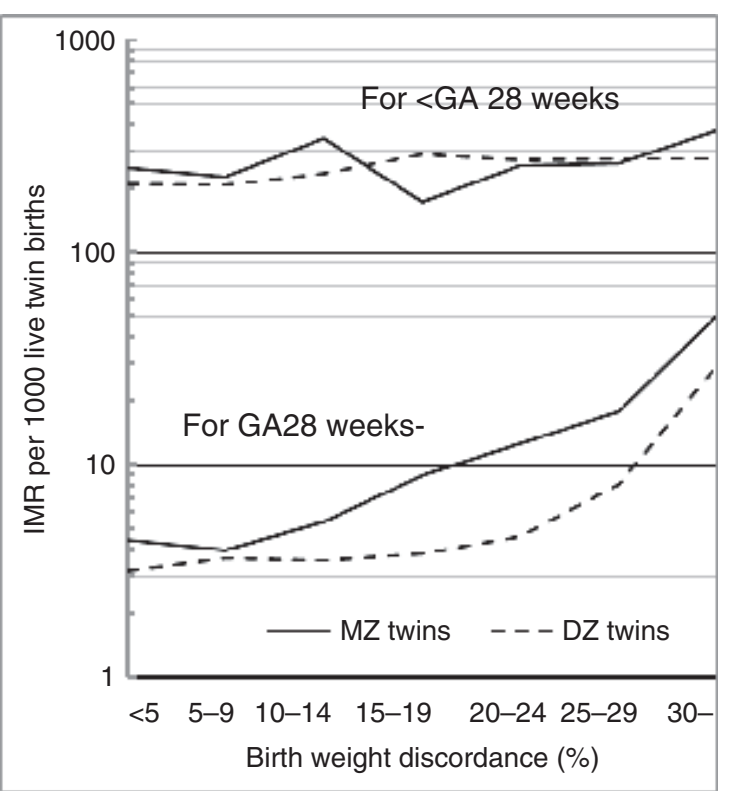

Fig. 1. Relationship between infant mortality rate (IMR) for zygotic twins and discordance levels among two gestational age groups ( $G A<28$ weeks and $G A \geq 28$ weeks).

BWD from $10-14 \%$ (5.4) to $\geq 30 \%$ (50.3), while the lowest IMR in DZ twins significantly increased with BWD from $20-24 \%$ (4.6) to $\geq 30 \%$ (29.6).

For births at $<28$ weeks, the proportions of $2 \mathrm{Ds}$ versus $\mathrm{D}$ were $0.52(432 / 826)$ versus $0.48(394 / 826)$ in $\mathrm{MZ}$ and $0.49(352 / 720)$ versus 0.51 (368/720) in DZ twins. The corresponding proportions for birth at $\geq 28$ weeks were $0.24(250 / 1032)$ versus $0.76(782 / 1032)$ in $\mathrm{MZ}$ and $0.08(72 / 900)$ versus $0.92(828 / 900)$ in DZ twins. This suggests that for births at $<28$ weeks, the proportion of the two categories (2Ds vs. D) was similar among both $\mathrm{MZ}$ and DZ twins, whereas for births at $\geq 28$ weeks, the proportions had an effect on the IMRs among MZ twins. See Figure 1.

\section{Relationship between IMRs and BWD Levels between Two Periods}

Table 4 shows the relationship between IMRs and BWD levels for MZ and DZ twins between two periods: 1995-2001 and 20022008. The proportions of infant deaths for old and recent periods were $59 \%$ (1100/1858) and $41 \%$ in MZ twins, respectively. The corresponding values were $52 \%(844 / 1620)$ and $48 \%$ in DZ twins. Then the ratios decreased by $7 \%$ in $\mathrm{MZ}$ and increased in DZ twins during the two periods. Decreased proportions of infant deaths in $\mathrm{MZ}$ twins led to a reduction in the total IMRs in the overall number of twins.

IMRs were significantly higher in $\mathrm{MZ}$ than in $\mathrm{DZ}$ twins in each BWD except at three BWD levels $(<15 \%)$ in the old period, whereas IMRs were significantly higher in MZ than in DZ twins in each BWD except at 5-9\% and $10-14 \%$ in the recent period. The lowest IMR in MZ twins was at 5-9\% (8.5 for old and 6.4 for the recent period). IMRs were significantly increased with BWD at $15-19 \%$ and thereafter in the old period and at $10-14 \%$ and thereafter in the recent period. In contrast, the lowest IMR in DZ twins was at 20-24\% (7.5) for the old and at $<5 \%(5.1)$ for the recent period. IMRs were significantly increased with BWD at $25-29 \%$ and $\geq 30 \%$ for the old period and were increased with BWD at $10-14 \%$ and thereafter in the recent period. As 
Table 2. Infant mortality rates for MZ and DZ twins according to birth weight discordance levels, 1995-2008

\begin{tabular}{|c|c|c|c|c|c|c|c|}
\hline \multirow{2}{*}{$\frac{2 \mathrm{Ds}}{\text { BWD (\%) }}$} & \multicolumn{2}{|c|}{ No. of infant deaths } & \multicolumn{2}{|c|}{ IMR } & \multirow{2}{*}{$\frac{M Z \text { vs. DZ twins }}{O R[95 \% \mathrm{Cl}]}$} & \multirow{2}{*}{$\frac{\mathrm{MZ} \text { twins }}{\text { OR }[95 \% \mathrm{Cl}]}$} & \multirow{2}{*}{$\frac{\mathrm{DZ} \text { twins }}{\mathrm{OR}[95 \% \mathrm{Cl}]}$} \\
\hline & MZ twins & DZ twins & MZ twins & DZ twins & & & \\
\hline$<5$ & 158 & 124 & 3.9 & 2.6 & $1.5^{*}[1.2,1.9]$ & $1.6 *[1.2,2.1]$ & $1.4 *[1.1,1.9]$ \\
\hline $5-9$ & 78 & 80 & 2.4 & 1.8 & $1.3[0.98,1.8]$ & Reference & Reference \\
\hline $10-14$ & 80 & 92 & 3.7 & 2.7 & $1.4 *[1.02,1.9]$ & $1.5 *[1.1,2.1]$ & $1.5^{*}[1.1,2.0]$ \\
\hline $15-19$ & 36 & 60 & 2.8 & 2.5 & $1.1[0.7,1.7]$ & $1.1[0.8,1.8]$ & $1.4[0.98,1.9]$ \\
\hline $20-24$ & 42 & 28 & 5.2 & 2.0 & $2.6^{*}[1.6,4.3]$ & $2.2 *[1.5,3.1]$ & $1.1[0.7,1.7]$ \\
\hline $25-29$ & 60 & 16 & 11.7 & 2.1 & $5.7^{*}[3.3,10.0]$ & $3.4 *[2.3,5.0]$ & $1.1[0.7,1.9]$ \\
\hline $30+$ & 228 & 24 & 32.7 & 2.7 & $12.7 *[8.3,19.3]$ & $14.0 *[10.8,18.1]$ & $1.5[0.9,2.3]$ \\
\hline Total & 682 & 424 & 5.3 & 2.3 & $2.3 *[2.1,2.6]$ & & \\
\hline D & \multicolumn{2}{|c|}{ No. of infant deaths } & \multicolumn{2}{|c|}{ IMR } & MZ vs. DZ twins & MZ twins & DZ twins \\
\hline BWD (\%) & MZ twins & DZ twins & MZ twins & DZ twins & OR $[95 \% \mathrm{Cl}]$ & OR $[95 \% \mathrm{Cl}]$ & OR $[95 \% \mathrm{Cl}]$ \\
\hline$<5$ & 196 & 196 & 4.8 & 4.1 & $1.1[0.9,1.4]$ & Reference & Reference \\
\hline $5-9$ & 163 & 226 & 5.1 & 5.2 & $1.0[0.8,1.2]$ & $1.1[0.9,1.3]$ & $1.3^{*}[1.04,1.5]$ \\
\hline $10-14$ & 126 & 186 & 5.8 & 5.4 & $1.1[0.9,1.3]$ & $1.2[0.99,1.6]$ & $1.3 *[1.1,1.6]$ \\
\hline $15-19$ & 120 & 130 & 9.2 & 5.4 & $1.7 *[1.3,2.2]$ & $2.0 *[1.6,2.5]$ & $1.3 *[1.1,1.7]$ \\
\hline $20-24$ & 123 & 84 & 15.2 & 5.9 & $2.6 *[2.0,3.4]$ & $3.3 *[2.6,4.1]$ & $1.4 *[1.1,1.9]$ \\
\hline $25-29$ & 95 & 78 & 18.5 & 10.0 & $1.9 *[1.4,2.5]$ & $4.0 *[3.1,5.2]$ & $2.5 *[1.9,3.2]$ \\
\hline $30+$ & 353 & 296 & 50.7 & 32.8 & $1.6 *[1.4,1.9]$ & $11.5^{*}[9.6,13.7]$ & $8.2 *[6.8,9.8]$ \\
\hline Total & 1176 & 1196 & 9.2 & 6.6 & $1.4 *[1.3,1.5]$ & & \\
\hline $2 \mathrm{Ds}+\mathrm{D}$ & \multicolumn{2}{|c|}{ No. of infant deaths } & \multicolumn{2}{|c|}{ IMR } & MZ vs. DZ twins & MZ twins & DZ twins \\
\hline BWD (\%) & MZ twins & DZ twins & MZ twins & DZ twins & OR $[95 \% \mathrm{Cl}]$ & $O R[95 \% \mathrm{Cl}]$ & OR $[95 \% \mathrm{Cl}]$ \\
\hline$<5$ & 354 & 320 & 8.7 & 6.7 & $1.3 *[1.1,1.5]$ & $1.2[0.98,1.4]$ & Reference \\
\hline $5-9$ & 241 & 306 & 7.5 & 7.0 & $1.1[0.9,1.3]$ & Reference & $1.0[0.9,1.2]$ \\
\hline $10-14$ & 206 & 278 & 9.4 & 8.0 & $1.2[0.98,1.4]$ & $1.3 *[1.1,1.5]$ & $1.2 *[1.02,1.4]$ \\
\hline $15-19$ & 156 & 190 & 11.9 & 7.9 & $1.5 *[1.2,1.9]$ & $1.6 *[1.3,2.0]$ & $1.2[0.99,1.4]$ \\
\hline $20-24$ & 165 & 112 & 20.5 & 7.9 & $2.6 *[2.1,3.3]$ & $2.8^{*}[2.3,3.4]$ & $1.2[0.9,1.5]$ \\
\hline $25-29$ & 155 & 94 & 30.2 & 12.1 & $2.5^{*}[2.0,3.3]$ & $4.1 *[3.4,5.1]$ & $1.8 *[1.4,2.3]$ \\
\hline $30+$ & 581 & 320 & 83.4 & 35.5 & $2.6 *[2.3,3.0]$ & $12.1 *[10.4,14.1]$ & $5.4 *[4.6,6.3]$ \\
\hline Total & 1858 & 1620 & 14.5 & 9.0 & $1.6 *[1.5,1.8]$ & & \\
\hline
\end{tabular}

Note: $2 \mathrm{Ds}$ are twin pairs with live births and infant deaths. $\mathrm{D}$ is a twin pair with live births but only one infant death. IMR (infant mortality rate) is the number of infant deaths per 1000 live twin births. $\mathrm{BWD}=$ birth weight discordance. $\mathrm{OR}=$ odds ratio. $\mathrm{Cl}=$ confidence interval.

${ }^{*} p<.05$.

for comparison between the old and the recent periods, the IMRs significantly decreased in the recent than in the old period except at $10-14 \%, 15-19 \%$ and $25-29 \%$ in MZ twins and at $15-19 \%$, $20-24 \%$ and $\geq 30 \%$ in DZ twins.

\section{Discussion}

In Caucasians, approximately $75 \%$ live intrapair twins showed BWD of $<15 \%$ between co-twins (concordant), 20\% were $15-$ $24 \%$ (mildly) discordant and approximately 5\% were $\geq 25 \%$ (severely) discordant (Blickstein \& Kalish, 2003). Tobe et al (2010) reported that severe discordance was $10.2 \%$ from 2001 to 2005 in the Japanese population, a value that was two times higher than that found in Caucasians. Table 1 shows that severe discordance was estimated as $9.4 \%$ in $\mathrm{MZ}, 9.3 \%$ in $\mathrm{DZ}$ and $9.3 \%$ in overall twins. Similarly, mild discordance was $19.2 \%$ and concordance was $71.5 \%$ for the overall Japanese population. Blickstein and Kalish
(2003) reported proportions of mild discordance that were similar to the results of the present study. In contrast, the proportion of severe discordance was two times higher in Japanese infants than in Caucasian infants, as shown in the results of Tobe et al. (2010) and the present study.

Table 2 shows that BWD and adverse IMR in MZ twins were obtained at $10-14 \%$ and thereafter. As for DZ twins, the same association was obtained at $10-14 \%, 25-29 \%$ and $\geq 30 \%$. In contrast, at GA $<28$ weeks, shown in Table 3, the relationship between BWD levels and adverse IMRs was obtained at $20-24 \%$ and thereafter in MZ twins, whereas the relationship in DZ twins was only obtained at $15-19 \%$ and $\geq 30 \%$. This suggests that at GA $<28$ weeks, a short GA may be a risk factor for IMRs in DZ twins rather than BWD.

Tables 2 and 3 show that the proportions of infant deaths at $\mathrm{GA}<28$ weeks were $44.5 \%(826 / 1858)$ in $\mathrm{MZ}$ and $44.4 \%(720 /$ $1620)$ in DZ twins. Similarly, the corresponding proportions at $\mathrm{GA} \geq 28$ weeks were $55.6 \%(1032 / 1858)$ and $55.5 \%(900 / 1620)$, 
Table 3. Relationship between infant mortality rates in MZ and DZ twins and discordance levels among two gestational age groups, 1995-2008

\begin{tabular}{|c|c|c|c|c|c|c|c|c|c|c|c|c|c|c|c|c|c|c|c|c|c|}
\hline \multirow{2}{*}{$\frac{<\mathrm{GA} 28 \mathrm{~W}}{\mathrm{BWD}(\%)}$} & \multicolumn{2}{|c|}{ 2Ds } & \multicolumn{2}{|c|}{ IMR } & \multicolumn{3}{|c|}{$O R[95 \% \mathrm{Cl}]$} & \multicolumn{2}{|c|}{ D } & \multicolumn{2}{|c|}{ IMR } & \multicolumn{3}{|c|}{$O R[95 \% \mathrm{Cl}]$} & \multicolumn{2}{|c|}{$2 D s+D$} & \multicolumn{2}{|c|}{ IMR } & \multicolumn{3}{|c|}{ OR $[95 \% \mathrm{Cl}]$} \\
\hline & MZ & DZ & MZ & DZ & MZ vs. DZ & MZ twins & DZ twins & MZ & DZ & $\mathrm{MZ}$ & DZ & MZ vs. DZ & MZ twins & DZ twins & $\mathrm{MZ}$ & $\mathrm{DZ}$ & MZ & DZ & MZ vs. DZ & MZ twins & DZ twins \\
\hline$<5$ & 98 & 96 & 140.2 & 117.6 & $1.2[0.9,1.7]$ & $2.3 *[1.3,4.0]$ & $1.3[0.8,2.2]$ & 78 & 76 & 111.6 & 93.1 & $1.2[0.9,1.7]$ & $1.0[0.7,1.7]$ & Reference & 176 & 172 & 251.8 & 210.8 & $1.3[0.99,1.6]$ & $1.6 *[1.1,2.3]$ & $1.0[0.8,1.3]$ \\
\hline $5-9$ & 60 & 68 & 117.6 & 93.5 & $1.3[0.9,1.9]$ & $1.9 *[1.1,3.3]$ & $1.03[0.6,1.7]$ & 56 & 82 & 109.8 & 113.3 & $1.0[0.7,1.4]$ & $1.0[0.6,1.7]$ & $1.2[0.9,1.7]$ & 116 & 150 & 227.5 & 207.2 & $1.1[0.9,1.5]$ & $1.4[0.9,2.1]$ & Reference \\
\hline 10-14 & 48 & 72 & 184.6 & 107. & $1.9 *[1.3,2.8]$ & $3.2 *[1.8,5.8]$ & $1.2[0.7,2.0]$ & 42 & 86 & 161.5 & 128.0 & $1.3[0.9,2.0]$ & $1.6[0.9,2.7]$ & $1.4 *[1.03,2.0]$ & 90 & 158 & 346.2 & 235.1 & $1.7 *[1.3,2.4]$ & $2.5 *[1.7,3.8]$ & $1.2[0.9,1.5]$ \\
\hline 15-19 & 16 & 52 & 66.1 & 151.2 & $0.4 *[0.2,0.7]$ & Reference & $1.8^{*}[1.0,3.0]$ & 26 & 48 & 107.4 & 139.5 & $0.7[0.5,1.2]$ & Reference & $1.6 *[1.1,2.3]$ & 42 & 100 & 173.6 & 290.7 & $0.5 *[0.3,0.8]$ & Reference & $1.6 *[1.2,2.1]$ \\
\hline $20-24$ & 24 & 28 & 91.6 & 159. & $0.5 *[0.3,0.95]$ & $1.4[0.7,2.8]$ & $1.9 *[1.0,3.5]$ & 43 & 20 & 164.1 & 113.6 & $1.5[0.9,2.7]$ & $1.6[0.97,2.7]$ & $1.3[0.7,2.1]$ & 67 & 48 & 255.7 & 272.7 & $0.9[0.6,1.4]$ & $1.6 *[1.1,2.5]$ & $1.4[0.98,2.1]$ \\
\hline $25-29$ & 36 & 16 & 137.4 & 137.5 & $1.0[0.5,1.9]$ & $2.3 *[1.2,4.2]$ & $1.6[0.8,3.2]$ & 33 & 16 & 126.0 & 137.9 & $0.9[0.5,1.7]$ & $1.2[0.7,2.1]$ & $1.6[0.97,2.8]$ & 69 & 32 & 263.4 & 275.9 & $0.9[0.6,1.5]$ & $1.7 *[1.1,2.6]$ & $1.5[0.9,2.3]$ \\
\hline $30+$ & 150 & 20 & 212.2 & 91.7 & $2.7 *[1.6,4.4]$ & $3.8 *[2.2,6.5]$ & Reference & 116 & 40 & 164.1 & 183.5 & $0.9[0.6,1.3]$ & $1.6 *[1.04,2.6]$ & $2.2 *[1.4,3.3]$ & 266 & 60 & 376.2 & 275.2 & $1.6^{*}[1.1,2.2]$ & $2.9 *[2.0,4.1]$ & $1.5 *[1.03,2.1]$ \\
\hline Total & 432 & 352 & 146.8 & 114.8 & $1.3^{*}[1.1,1.5]$ & & & 394 & 368 & 133.9 & 120.0 & $\begin{array}{ll}0 & 1.1[0.97,1.3]\end{array}$ & & & 826 & 720 & 280.7 & 234.8 & $1.3^{*}[1.1,1.4]$ & & \\
\hline GA $28 \mathrm{~W}$ & \multicolumn{2}{|c|}{ 2Ds } & \multicolumn{2}{|c|}{ IMR } & \multicolumn{3}{|c|}{$O R[95 \% \mathrm{Cl}]$} & \multicolumn{2}{|c|}{ D } & \multicolumn{2}{|c|}{ IMR } & \multicolumn{3}{|c|}{ OR $[95 \% \mathrm{Cl}]$} & \multicolumn{2}{|c|}{$2 \mathrm{Ds}+\mathrm{D}$} & \multicolumn{2}{|c|}{ IMR } & \multicolumn{3}{|c|}{$O R[95 \% \mathrm{Cl}]$} \\
\hline BWD (\%) & MZ & DZ & MZ & DZ & MZ vs. DZ & MZ twins & DZ twins & $\mathrm{MZ}$ & DZ & MZ & DZ & MZ vs. DZ & MZ twins & DZ twins & MZ & DZ & MZ & DZ & MZ vs. DZ & MZ twins & DZ twins \\
\hline$<5$ & 60 & 28 & 1.5 & 0.6 & $2.6 *[1.7,4.1]$ & $2.7^{*}[1.6,4.5]$ & $2.2 *[1.1,4.2]$ & 118 & 120 & 2.9 & 2.6 & $1.1[0.9,1.5]$ & Reference & Reference & 178 & 148 & 4.4 & 3.2 & $1.4 *[1.1,1.7]$ & $1.1[0.9,1.4]$ & Reference \\
\hline $5-9$ & 18 & 12 & 0.6 & 0.3 & $2.1 *[1.0,4.3]$ & Reference & Reference & 107 & 144 & 3.4 & 3.3 & $1.0[0.8,1.3]$ & $1.2[0.9,1.5]$ & $1.3^{*}[1.0,1.7]$ & 125 & 156 & 3.9 & 3.6 & $1.1[0.9,1.4]$ & Reference & $1.1[0.9,1.4]$ \\
\hline 10-14 & 32 & 20 & 1.5 & 0.6 & $2.6 *[1.5,4.6]$ & $2.7^{*}[1.5,4.7]$ & $2.1 *[1.0,4.3]$ & 84 & 100 & 3.9 & 2.9 & $1.3[0.99,1.8]$ & $1.3 *[1.0,1.8]$ & $1.2[0.9,1.5]$ & 116 & 120 & 5.4 & 3.5 & $1.5 *[1.2,2.0]$ & $1.4^{*}[1.1,1.8]$ & $1.1[0.9,1.4]$ \\
\hline 15-19 & 20 & 8 & 1.6 & 0.3 & $4.6 *[2.0,10.5]$ & $2.8^{*}[1.5,5.2]$ & $1.2[0.4,3.0]$ & 94 & 82 & 7.3 & 3.5 & $2.1 *[1.6,2.9]$ & $2.5 *[1.9,3.3]$ & $1.4 *[1.02,1.8]$ & 114 & 90 & 8.9 & 3.8 & $2.3 *[1.8,3.1]$ & $2.3^{*}[1.8,2.9]$ & $1.2[0.9,1.6]$ \\
\hline $20-24$ & 18 & 0 & 2.3 & 0.0 & - & $4.1^{*}[2.1,7.8]$ & - & 80 & 64 & 10.2 & 4.6 & $2.3^{*}[1.6,3.1]$ & $3.5 *[2.6,4.7]$ & $1.8^{*}[1.3,2.4]$ & 98 & 64 & 12.6 & 4.6 & $2.8 *[2.0,3.8]$ & $3.2 *[2.5,4.2]$ & $1.4 *[1.1,1.9]$ \\
\hline $25-29$ & 24 & 0 & 4.9 & 0.0 & - & $8.7^{*}[4.7,16.1]$ & - & 62 & 62 & 12.7 & 8.1 & $1.6 *[1.1,2.3]$ & $4.4 *[3.2,6.0]$ & $3.2 *[2.3,4.3]$ & 86 & 62 & 17.7 & 8.1 & $2.2 *[1.6,3.1]$ & $4.6 *[3.5,6.0]$ & $2.6 *[1.9,3.5]$ \\
\hline $30+$ & 78 & 4 & 12.5 & 0.5 & $27.8 *[10.2,75.8]$ & $22.3 *[13.3,37.2]$ & $1.6[0.5,5.1]$ & 237 & 256 & 37.9 & 29.1 & $1.3^{*}[1.1,1.5]$ & $13.6 *[10.9,16.9]$ & $11.7^{*}[11.4,11.9]$ & 315 & 260 & 50.3 & 29.6 & $1.7 *[1.6,1.9]$ & $14.4 *[11.7,17.7]$ & $9.6 *[9.4,9.8]$ \\
\hline Total & 250 & 72 & 2.0 & 0.4 & $4.9 *[3.8,6.4]$ & & & 782 & 828 & 6.3 & 4.7 & $1.3^{*}[1.2,1.4]$ & & & 1032 & 900 & 8.2 & 5.1 & $1.6 *[1.5,1.7]$ & & \\
\hline
\end{tabular}

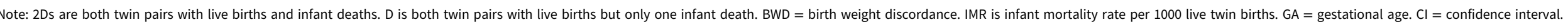
${ }^{*} p<.05$. 
Table 4. Relationship between infant mortality rates in zygotic twins and discordance levels for 1999-2001 and 2002-2008

\begin{tabular}{|c|c|c|c|c|c|c|c|c|}
\hline \multirow{2}{*}{$\frac{1995-2001}{B W D(\%)}$} & \multicolumn{2}{|c|}{ No. of infant deaths } & \multicolumn{2}{|c|}{ Infant mortality rate } & \multicolumn{4}{|c|}{ OR (95\% confidence interval) } \\
\hline & MZ twins & DZ twins & MZ twins & DZ twins & MZ vs. DZ twins & MZ twins & DZ twins & MZ (Old vs. Recent) \\
\hline$<5$ & 201 & 184 & 9.6 & 8.8 & $1.1[0.9,1.3]$ & $1.1[0.9,1.3]$ & $1.2[0.8,1.5]$ & $1.3^{*}[1.1,1.5]$ \\
\hline $10-14$ & 119 & 148 & 10.5 & 9.7 & $1.1[0.8,1.3]$ & $1.2[0.99,1.5]$ & $1.3[0.96,1.6]$ & $1.3[0.99,1.6]$ \\
\hline $15-19$ & 91 & 96 & 13.2 & 9.0 & $1.5^{*}[1.2,1.8]$ & $1.6 *[1.3,1.8]$ & $1.2[0.8,1.5]$ & $1.3[0.9,1.6]$ \\
\hline $25-29$ & 85 & 56 & 30.5 & 16.6 & $1.9 *[1.5,2.2]$ & $3.7^{*}[3.4,3.9]$ & $2.2^{*}[1.8,2.6]$ & $1.0[0.7,1.3]$ \\
\hline $30+$ & 355 & 136 & 90.8 & 35.1 & $2.7 *[2.5,3.0]$ & $11.6 *[11.4,11.8]$ & $4.8 *[4.5,5.1]$ & $1.3 *[1.1,1.4]$ \\
\hline Total & 1100 & 844 & 16.6 & 10.6 & $1.6 *[1.5,1.7]$ & & & $1.4 *[1.2,1.5]$ \\
\hline $2002-2008$ & \multicolumn{2}{|c|}{ No. of infant deaths } & \multicolumn{2}{|c|}{ Infant mortality rate } & \multicolumn{4}{|c|}{ OR (95\% confidence interval) } \\
\hline BWD (\%) & MZ twins & DZ twins & MZ twins & DZ twins & MZ vs. DZ twins & MZ twins & DZ twins & DZ (Old vs. Recent) \\
\hline $10-14$ & 87 & 130 & 8.3 & 6.7 & $1.2[0.96,1.5]$ & $1.3^{*}[1.0,1.6]$ & $1.3 *[1.1,1.6]$ & $1.5^{*}[1.2,1.7]$ \\
\hline $15-19$ & 65 & 94 & 10.5 & 7.1 & $1.5^{*}[1.2,1.8]$ & $1.6^{*}[1.3,2.0]$ & $1.4 *[1.1,1.7]$ & $1.3[0.98,1.6]$ \\
\hline $20-24$ & 54 & 64 & 14.7 & 8.2 & $1.8 *[1.4,2.2]$ & $2.3^{*}[2.0,2.6]$ & $1.6 *[1.3,1.9]$ & $0.9[0.5,1.3]$ \\
\hline $25-29$ & 70 & 38 & 29.9 & 8.6 & $3.5^{*}[3.1,3.9]$ & $4.8^{*}[4.5,5.1]$ & $1.7 *[1.3,2.1]$ & $1.9 *[1.5,2.4]$ \\
\hline $30+$ & 226 & 184 & 74.0 & 35.8 & $2.2 *[2.0,2.4]$ & $12.4^{*}[12.1,12.6]$ & $7.2 *[7.0,7.4]$ & $0.98[0.8,1.2]$ \\
\hline Total & 758 & 776 & 12.3 & 7.7 & $1.6^{*}[1.5,1.7]$ & & & $1.4 *[1.3,1.5]$ \\
\hline
\end{tabular}

Note: $2 \mathrm{Ds}$ are both twin pairs with live births and infant deaths. $\mathrm{D}$ is both twin pairs with live births but only one infant death. BWD $=$ birth weight discordance. $O R=$ odds ratio. Infant mortality rate is the number of infant deaths per 1000 live twin births. Old is 1995-2001 and new is 2002-2008. ${ }^{\star} p<.05$.

respectively. As for GA $\geq 28$ weeks, the relationship between BWD and adverse IMR in MZ twins was obtained after 10-14\% in MZ twins and after $20-24 \%$ in DZ twins.

Table 4 shows that the IMR in MZ twins at $\geq 30 \%$ was significantly higher in the old (90.8) than in the recent (74.0) period, whereas the corresponding rates in $\mathrm{DZ}$ twins were the same (35-36). According to Sago (2008), over 300 babies with twinto-twin transfusion syndrome were treated with fetoscopic laser photocoagulation until April 2008 in Japan. After the operations on these babies, the proportion of survival rate at 6 months was $52 \%$ (75/144). The reduced IMRs in MZ twins during the two periods may be associated with the treatment with fetoscopic laser photocoagulation and medical care at $<5 \%, 5-9 \%, 20-24 \%$ and $\geq 30 \%$. For DZ twins, IMRs significantly decreased at $<5 \%$, $5-9 \%, 10-14 \%$ and $25-29 \%$ during the two periods which may be associated with medical care.

Acknowledgments. The author is grateful to the staff of Statistics and Information Department, Ministry of Health, Labour and Welfare in Japan.

\section{References}

Blickstein, I., \& Kalish, R. B. (2003). Birthweight discordance in multiple pregnancy. Twin Research, 6, 526-531.

Branum, A. M., \& Schoendorf, K. C. (2003). The effect of birth weight discordance on twin neonatal mortality. Obstetrics \& Gynecology, 101, 570-574.
Demissie, K., Ananth, C. V., Martin, J., Hanley, M. L., MacDorman, M. F., \& Rhoads, G. C. (2002). Fetal and neonatal mortality among twin gestations in the United States: The role of intrapair birthweight discordance. Obstetrics \& Gynecology, 100, 474-480.

Imaizumi, Y. (2015). Infant mortality of zygotic twins and influencing factors in Japan, 1995-2008. Gynecology \& Obstetrics, 5, 341.

Jahanfar, S., Lim, K., \& Ovideo-Joekes, E. (2017). Birth weight discordance and adverse perinatal outcomes. Journal of Perinatal Medicine, 45, 603-611.

Kato, N., \& Matsuda, T. (2006). The relationship between birthweight discordance and perinatal mortality of one of the twins in a twin pair. Twin Research and Human Genetics, 9, 292-297.

Kim, L. H., Caughey, A. B., Yee, L. M. \& Cheng, Y. W. (2019). Association between the degree of twin birthweight discordance and perinatal outcomes. American Journal of Perinatology, 36, 969-974.

Mazhar, S. B., \& Kanwal, S. (2010). Twin birth weight discordance: Associated factors and outcome. Journal of the College of Physicians and Surgeons Pakistan, 20, 391-394.

Sago, H. (2008). Fetoscopic laser photocoagulation for TTTS (in Japanese). Ninsanpushi, 60, 282-287.

Tobe, R.G., Mori, R., Shinozuka, N., Kubo, T., \& Itabashi, K. (2010). Birthweight discordance, risk factors and its impact on perinatal mortality among Japanese twins: Data from a national project during 2001-2005. Twin Research and Human Genetics, 13, 490-494.

Weinberg, W. (1901). Beitrage zu Physiologie und Pathologie der Mehrlingsgeburten beim Menschen. Archiv fuer die gesamte Physiolgie des Menschen und der Tiere, 88, 346-430. 